\title{
Team-Based Interactive Student Learning for Accounting Courses
}

\author{
Theresa Phipps \\ Slippery Rock University
}

Student engagement is difficult to achieve in an undergraduate accounting course, especially a class with a heavy proportion of millennials. In accounting courses, students tend to be disengaged and offer minimal voluntary participation, and yet from pedagogical research, student participation assists learning. To increase student participation, the instructor implemented small-group, team activities in several accounting classes. Research indicates that team activities may improve learning, but this approach had two other purposes: to get students to enjoy coming to the class and to practice working in groups, which is useful in the accounting profession. By both objective and subjective measures, this approach achieved favorable results. Comparing the classes with small-group teams and those without, the classes with the team learning scored higher on exams. Also, the students in the classes with smallgroup teams reported that the regular team activities were both their favorite and the most beneficial aspect of the class.

Keywords: Accounting, Team-based, Millennials, Small-group

\section{INTRODUCTION}

Students often do not participate in lecture-based classroom instruction, especially in an undergraduate accounting course. Introducing students to the language of accounting and General Accepted Accounting Principles can be very challenging for the instructor to teach and for the students to comprehend. Compounding the challenges of the subject matter is the lack of student involvement, which can make the class period seem boring, tiresome, and even painful -for everyone. However, active engagement in the classroom can help students understand the material by creating stronger connections between students. This paper consists of first-person observations by an accounting instructor who tried to make accounting entertaining. Based on pedagogical literature and along with an appreciation of the attitudes of millennials, this effort to enhance the teaching and learning of accounting hinges on transforming the classroom to an active learning environment through team-based problem solving and accounting games.

\section{LITERATURE REVIEW}

Pedagogically, active engagement in the classroom promotes deeper levels of processing and learning because it creates stronger connections (McGlynn, 2005). Students develop a personal understanding of the material by doing as opposed to striving to retain the material (Phillips \& Trainor, 2014). Passive 
learning, on the other hand, happens when students are listening to the material presented by an instructor and it does not facilitate deep learning (Lucas, 1997). To be effective, content delivery has to keep the students engaged and challenged both in and out of the classroom.

For undergraduate classes which currently consist principally of millennials, persons born between 1982 and 2002, it is also important to recognize research on millennial's attitudes and education. In an early study, Howe and Strauss suggest that millennial students have a preference for interactive and experiential learnings approaches (Howe \& Strauss, 2003). It has also been observed that the millennial generation is very comfortable with technology, is open to diversity, shares a global perspective, and has a desire for luxury items (Sandeen, 2008). Seven core traits that define the millennial generation are special, sheltered, confident, team-oriented, conventional, pressured, and achieving (Howe \& Strauss 2003). Several of those features have pedagogical significance. Millennials are motivated and achievement-oriented team-players, therefore, they prefer to study in groups, and to a degree that not observed before, they want hands-on, problem-based learning environment, as opposed to a passive classroom learning environment (Howe \& Strauss 2003). Because millennials prefer to learn and work in teams, they respond well to small group interactions in the classroom to study and complete project work. For millennials, cooperative learning exercises are recommended because those empower millennials to be decision-makers in the course (McGlynn, 2005).

Many faculty members are adjusting their teaching to be more engaging and experimentally because they are recognizing that millennial students learn differently than prior generations of students (Skiba \& Barton, 2006). To successfully implement a learning environment catered to millennials' interest in teamwork, it is beneficial to understand why teamwork has a greater appeal to them than to prior generations. One study found that millennials want to learn for fun and enrichment (Sandeem, 2008). Another study confirmed that the millennial generation has a quest for fun, has little tolerance for boredom, and seeks careers that are interesting and fun (Smith, 2008). Survey results also reveal that millennial students prefer a mixture of course activities including lecture, group work, discussion and problem-solving to enhance the learning experience (Nicholas, 2008). It is notable that millennials prefer to collaborate and work in teams with other millennials (Lancaster \& Stillman, 2000). With respect to the accounting students, Phillips \& Trainor report that millennials want instructors to provide more hands-on and practical applications of the accounting content covered in their courses (Phillips \& Trainor, 2014).

Millennials' learning interests and career objectives are in line with attributes currently required by employers. The workplace has been dramatically transformed by rapid technological advances, increasingly knowledge-intensive work, internationalization, global competition, and organizational restructuring and change (Umble et al., 2008). Employees need to be able to work in teams to make decisions, solve problems and think creatively. Many employers rank the ability to work with a group as one of the most important attributes for business school graduates (Chapman et al., 2006). Therefore, graduating students need to be equipped with team skills (Kalliath \& Laiken, 2006).

In addition to responding to their learning preferences, team-based projects and team-based works in the classroom can help millennial students develop those traits sought after by employers. Employers want employees to have social, communication and cooperative skills; the ability to decide what knowledge is necessary for a particular project or task, and the ability to acquire that knowledge and use it in an effective manner (Tynjala, 1999). By creating teams in the classroom, students learn how to work with each other to solve problems and present their answers to their peers. It is also notable that the effective application of vital competencies such as critical thinking, creativity, communication, and collaboration at the workplace is more likely if these skills have been acquired in college (Blair, 2012).

\section{PARTICIPANTS}

This study consists of undergraduate students at a large (9,900 student), rural, public university in the Northeastern United States. It involves 182 universal millennial students in the college of business who enrolled in introductory and upper-level accounting classes taught in 2017 as part of a four-year accounting curriculum. 


\section{PROCESS}

The central methodology for this study rests on a comparison between two teaching approaches for the same accounting classes; passive learning lectures versus interactive small-group teamwork. In fall 2017, I taught finance and tax accounting courses using a lecture-based approach with PowerPoint presentations for the first half of the semester. Midway through the semester, in an effort to enhance student participation and understanding, I pivoted to a small-group, team-based approach to those classes. For each class, I divided the students into teams of five or six to complete assignments within their team. In class, I would still begin with an abbreviated lecture distilled to the key points, but then for the remainder of the period, the students would work in their teams to complete exercises based on the lecture and present their answers to the class. Specifically, each of the in-class assignments was based on the concept just taught. During the activity section, I would move among the groups providing guidance and answering questions as needed. I observed that within the teams, the students truly collaborated in working on the problems together. They also peer-instructed each other in which if one student did not understand a topic, then the teammates would share their understanding of the concept. I found that this method increased student preparation for the class because students would come to class having completed the readings, and they were ready to use and apply those concepts. This approach enabled me to have real-time feedback about my teaching and to observe how students understand those concepts. Therefore, if I noticed that several groups were struggling with a concept, then I had an opportunity to provide an explanation for the entire class. At the end of the class, each group would select a representative to present the team's analysis of the problem and write their answer on the board. In order to engage the whole team, it was required that everybody in the team participated as a presenter. During the student's presentation, other students could ask questions to gain a better understanding of the concept.

In addition to the team-based gradual learning, I also used a team-based approach for cumulative reviews. Recognizing that millennials want to enjoy learning, in review for the chapter, we would have an in-class competition among the teams to complete old exam problems for points. I used prior exam questions on PowerPoint slides to provide an opportunity for each team to answer the specific question and therefore could gain an additional point for the correct answer. If the answer was incorrect, then the question was up for grabs, and the first volunteer team that provided the correct answer would receive a point. At the end of the game, each team that had the most points got corresponding bonus points on their next exam. The competition was intense among the student teams to gain bonus points which led to exciting classes.

\section{RESULTS}

My strongest impression of this pedagogical pivot was that the students truly enjoyed the chapter review competitions. When asked about their favorite part of the class, several students identified those games with the following quotes:

- "I liked the games and bonus opportunities."

- "The reviews for each chapter were very helpful and I learned a lot."

- "My favorite part of the class was the games we do in teams."

- "My favorite thing was the in-class games and exercises because it really helps me to understand the material better."

- "The team games played at the end of class."

- "I like the review games! They were always fun!"

- "I enjoyed how hands-on the class is."

Consistent with the findings by Haywood et al., the students maintained interest and were involved in the learning process when the games were used to make learning fun (Haywood et al., 2004). Similar to Freeman et al. who found that active learning methods improve the performance of students by an 
average of one half a letter grade (Freeman et al., 2014), the students' exam grades also improved by an average of one half a letter grade after implementing the team activities. Consistent with Prince who observed that students remember more content if brief activities are introduced to the lecture (Prince, $\mathrm{p}$. $229,2004)$, the students learned the concepts better after doing the team activities.

While the games may have been the student's favorite part, the in-class group work was also valuable. They got to know each other, learned from each other, built identities as teammates, had instruction responsive to their needs, and practiced working together on business problems. They developed small-group and large-group communication skills because everyone had to participate. The game regulation implied that no one could present on the board twice and it had to be a different student every time. The students spoke to each other in the groups to complete the activities and if it was their turn, they had to present their answer to the class. In addition, the competitions provided extra motivation, but it also taught the students about accountability to their peers. For example, sometimes during the competitions, a student provided an incorrect answer before consulting with his or her team which would cost the team a point. While many of these results are not readily quantifiable, I have followed a smallgroup team-based approach in every subsequent accounting course that I teach.

\section{ISSUES}

The obstacles to this small-group team-based approach mostly relate to the additional labor involved. First, this approach is more time-intensive. The instructor has to know more than just the subject matter, he or she must distill the concepts into the most important ideas for targeted instruction and then plan out the in-class exercises. The review competitions also require additional time to prepare and review those questions, and the competitions force the instructor to take on the additional responsibility of in-class referee for the scoring system.

\section{CONCLUSION}

The approach was not complex. The students participated in active learning through team-based problem solving and accounting games. The students actually enjoyed the accounting games which spurred competition and participation among the students. The students' exams scores improved by an average of one half a letter grade after implementing the small-group team exercises and games. The collateral benefits were abundant; students learned to collaborate, prepared them for teamwork in the workplace, helped build communication skills, and encouraged accountability to their peers. To summarize, the students and the instructor enjoyed class more. 


\section{REFERENCES}

Blair, N. (2012). Technology integration for the new 21st century learner. Principal, 91(3), 8-13.

Chapman, K. J., Meuter, M., Toy, D., \& Wright, L. (2006). Can’t we pick our own groups? The influence of group selection method on group dynamics and outcomes. Journal of Management Education, 30(4), 557-569.

Freeman, S., \& Wenderoth, M. P., et al. (2014). Active learning increases student performance in science, engineering, and mathematics. Proceedings of the National Academy of Sciences, 111(23), 84108415.

Haywood, M. E., McMullen, D. A., \& Wygal, D. E. (2004). Using games to enhance student understanding of professional and ethical responsibilities. Issues in Accounting Education, 19(1), 85-99.

Howe, N., \& Strauss, W. (1992). Generations: The history of America's future, 1584 to 2069. Harper Collins.

Howe, N., \& Strauss, W. (2000). Millennials rising: The next great generation. Vintage.

Howe, N., \& Strauss, W. (2003). Millennials go to college: Strategies for a new generation on campus: Recruiting and admissions, campus life, and the classroom. Washington, DC: American Association of Collegiate Registrars and Admissions Officers.

Kalliath, T., \& Laiken, M. (2006). Use of teams in management education.

Lancaster, L. C., \& Stillman, D. (2002). When generations collide: Who they are. Why they.

Lucas, U. (1997). Active learning and accounting educators. ACCOUNTING EDUCATION-LONDON, 6 , 189-190.

Nicholas, A. (2008). Preferred learning methods of the millennial generation.

Phillips, C. R., \& Trainor, J. E. (2014). Millennial students and the flipped classroom. ASBBS Proceedings, 21(1), 519.

Prince, M. (2004). Does active learning work? A review of the research. Journal of engineering education, 93(3), 223-231.

Sandeen, C. (2008). Boomers, Xers, and Millennials: Who Are They and What Do They Really Want from Continuing Higher Education? Continuing Higher Education Review, 72, 11-31.

Skiba, D. J., \& Barton, A. J. (2006). Adapting your teaching to accommodate the next generation of learners. Online Journal of Issues in Nursing, 11(2), 15.

Smith, W.S. (2008). Decoding Generational Difference. New York: Deloit Development LLC.

Tynjälä, P. (1999). Towards expert knowledge? A comparison between a constructivist and a traditional learning environment in the university. International journal of educational research, 31(5), 357442.

Umble, E. J., Umble, M., \& Artz, K. (2008). Enhancing Undergraduates' Capabilities Through TeamBased Competitions: The Edward Jones Challenge. Decision Sciences Journal of Innovative Education, 6, 1-27. doi:10.1111/j.1540-4609.2007.00164.x 


\section{APPENDIX A - IRB APPROVAL}

Protocol \#: 2019-N50-51-A

Protocol Title: Interactive Student Teams for Accounting Classes

The Institutional Review Board (IRB) of Slippery Rock University received the requested modifications to the above-referenced protocol.

The IRB has reviewed the modifications and approved the protocol under the EXEMPT category of review.

You may begin your project as of June 4, 2019. Your protocol will automatically close on June 3, 2020, unless you request, in writing, to keep it open.

Please contact the IRB Office by phone at (724)738-4846 or via email at irb@sru.edu should your protocol change in any way. Your formal letter will be sent via interoffice mail.

Thanks,

Casey

\section{Casey Hyatt}

Grants and Sponsored Research/

Institutional Review Board (IRB)/

Institutional Animal Care and Use Committee (IACUC)

Secretary

Slippery Rock University

1 Morrow Way

008 Old Main

Slippery Rock, PA 16057

Grants Office Direct Line: 724-738-2045

IRB \& IACUC Office Direct Line: 724-738-4846

Fax: 724-738-4857

www.sru.edu 